\title{
Relationship between Depression and Aging Awareness among Frail Older Adults Living Alone in Japan
}

\author{
Yumi Okinaka \\ Graduate School of Health Sciences, Okayama University, Okayama, Japan \\ Email: okky@okayama-u.ac.jp
}

How to cite this paper: Okinaka, Y. (2018) Relationship between Depression and Aging Awareness among Frail Older Adults Living Alone in Japan. Health, 10, 1539-1553. https://doi.org/10.4236/health.2018.1011117

Received: October 17, 2018

Accepted: November 19, 2018

Published: November 22, 2018

Copyright $\odot 2018$ by author and Scientific Research Publishing Inc. This work is licensed under the Creative Commons Attribution International License (CC BY 4.0).

http://creativecommons.org/licenses/by/4.0/

\begin{abstract}
Aim: This study aimed to clarify the relationship between depression and aging awareness among older adults living alone with low-level long-term-care needs. Methods: Participants were older adults aged 65 years and older in Japan. Data were collected via an anonymous questionnaire. Participants were categorized based on their long-term care need level, from Support 1 to Care 2 according to the care insurance criteria in Japan. The questionnaire included: 1) the Geriatric Depression Scale-Short Version-Japanese (GDS); 2) items on aging life satisfaction at present, and positive and negative aging awareness in the past (when they were young); 3) the SF-8 to assess health-related quality of life; 4) the Lubben Social Network Scale-6 (LSNS-6); and 5) items on the use of care services. Data were analyzed using multiple logistic regression analysis. Results: In total, 457 participants were recruited. Their mean age was $83.9 \pm 6.5$ years; $39.8 \%$ of the participants had a GDS score of 6 and above. In the regression analysis, the GDS score significantly correlated with aging life satisfaction at present, negative aging awareness in the past, mental health, and social networks. Conclusion: Older adults living alone who have positive views of their current lives and lacked negative views of aging in their younger years were resistant to depression after being certified as requiring low-level long-term care. Preventing and improving depression in this population requires community-based support to expand their social networks and to help individuals of all ages view the aging process positively.
\end{abstract}

\section{Keywords}

Depression, Older Adult, Aging Awareness, Living Alone, Frail

\section{Introduction}

The number of patients with mood disorders has nearly doubled in the last dec- 
ade in Japan [1]. Older adults have a high risk of depression. A depressive state can make daily life difficult, and it results in a decline in quality of life (QOL). Prevention and treatment of depression in older adults are a serious social issue in Japan.

Depression not only has negative effects on frail syndrome [2]; it is exacerbated in older adults with chronic diseases if they lack poor spousal and family support [3]. In essence, solitary older adults-those who do not live with a spouse or family members-are highly prone to depression.

Prior research concerning depressive states in older adults have found a higher tendency for depression in older adults living in the community than in those who reside in elderly-care facilities [4], in addition to a $10 \%$ increase in the number of elderly with a depressive state over a two-year period [5]. Others have reported that the health problems that occur among the older elderly in Japan can more easily trigger a depressive state [6]; physical functions of the older adults decline by $30 \%$ in men in three years, and by $50 \%$ in women in the same duration [7]. One can thus say that older adults residing in the community are more prone to depression than persons who live in facilities, where daily support is provided.

Other factors also make it easy for older adults to become depressed, including social isolation, which also leads to a decline in mental functions. Risk factors for social isolation include living alone, worsening health, and life events such as loss and separation by death [8]. Depressed older adults in Japan are, in many cases, living alone [9]. Some studies suggest the possibility of preventing depression in older adults living alone via social support, family, friends, and daycare services [9] [10].

Depression in older adults can also be influenced by their past and present attitudes towards aging, sometimes called aging awareness. In essence, older adults would have gone through a variety of experiences of loss, and while adjusting to changes in their social environment, they are faced with their own aging. Consequently, they must directly confront the psychosocial developmental issue of integrating the entirety of their lives [11]. As older adults transition from an autonomous life to one requiring care, they increasingly face difficulties in daily life experiences, along with the need to adapt to the changes brought about by aging, including those concerning personal health.

Further, against the backdrop of ageism and amidst the workings of social interactions, people form a consciousness of values about aging [12] [13]. Older adults with depression report that unforgettable negative experiences from several decades in the past have triggered their current depression [14] [15]. Thus, the awareness of negative past experiences may be causing mental disorders in frail older adults, making them particularly vulnerable to depression.

Other studies describe the relationship between depression and the subjective feelings of happiness among older adults living in the community, and subjective feelings of health and satisfaction with daily life among hospitalized older adults [4] [16] [17]. The current level of life satisfaction and feelings of happiness 
among older adults is related to the positive meanings that they attribute to aspects such as the self and the experiences they have accumulated throughout life. In other words, healthy older adults with a high level of satisfaction with daily life and those who view aging positively may not become depressed easily.

According to the theory of social gerontology, when older adults are able to manage changes in their physical and mental states, isolation, involvement in activities in the community, and social support, they can successfully adapt to aging, grow, and develop. However, when they are unable to adapt to these changes, they may fall into depression and even commit suicide. The successful adaptation of older adults can be judged by their high level of life satisfaction and feelings of having achieved a good life [18]. Thus, how older adults choose to live their life is determined by their awareness.

Accordingly, depression in solitary older adults with low-level long-term-care needs may be influenced by their past and present attitudes towards aging, mediated by their general health, social isolation, and social support.

The present study aimed to clarify the relationship between depression and aging awareness in older adults with low-level long-term-care needs. Our findings should serve as a valuable reference for those considering strategies to reduce depression in this population. Moreover, our discussion on how the rising numbers of older adults with long-term-care requirements are living in the later stages of their life, as well as suggestions regarding strategies to assist them hold great significance.

The objective of this study was to clarify the relationship between depression and past and present aging awareness among older adults living alone and in need of low-level long-term care.

The predicted relationship between depression and aging awareness were validated through four analytic models (Figure 1).

\section{Research Method}

\subsection{Study Design}

Using a cross-sectional design, a hypothesis explorative analysis was conducted in the present study.

\subsection{Setting and Participants}

This study utilized a questionnaire survey developed based on several constructs from a research framework related to the health and lifestyles of solitary older adults. In this study, depressive state as a dependent variable was used. Surveys were distributed in three prefectures (A-C) in Japan's Chugoku and Shikoku regions, having higher aging rates (i.e., proportion of population 65 years or older) than the national averageat the investigation; approximately $30 \%$ in A, $26 \%$ in B, and $28 \%$ in C. Single-person households occupied by adults aged 65 years or older comprise approximately $13 \%, 15 \%$, and $18 \%$ of all households in these respective prefectures; slightly lower than the national average, yet higher than that in the past years [19]. 

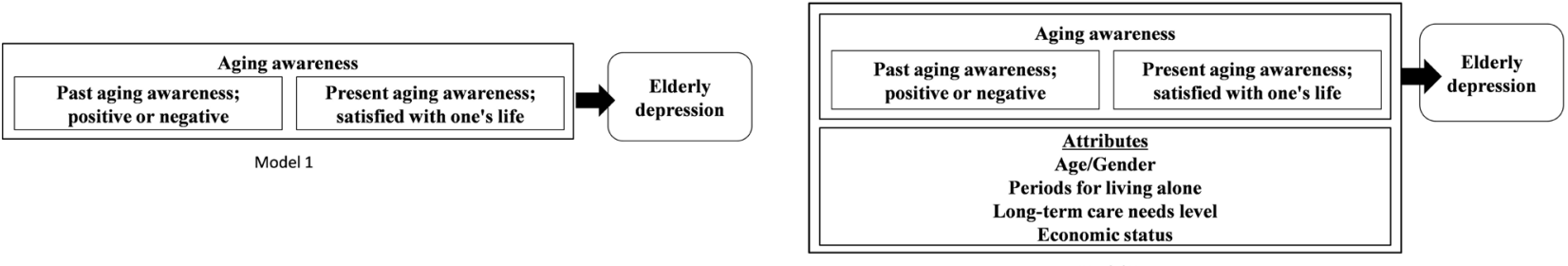

Model 2
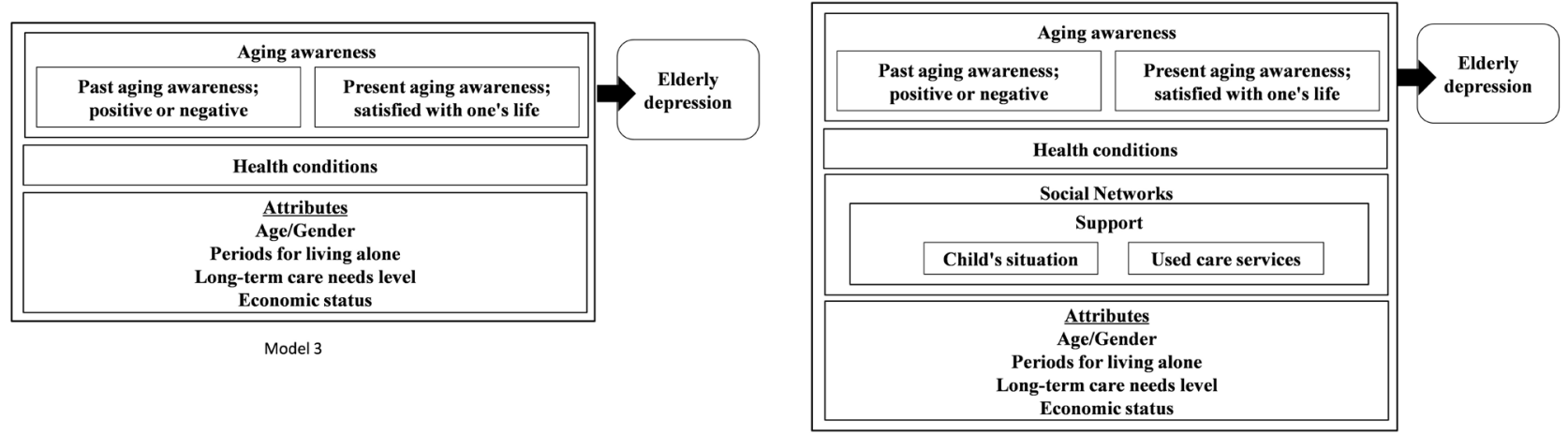

Model 4

Figure 1. The analysis model of this study.

Subjects were solitary older adults aged 65 years or older who utilized a community general support center or in-home long-term care support providers in one of these prefectures. Japan's Long-term Care Insurance Act provides services through community general support centers to prevent the need for long-term care among older adults. Used by older adults who do not require long-term care and those certified to require only support alike, each center is located in a separate "school zone," as defined by the nearest public junior high school. In-home long-term care support providers employ care managers to organize care services and prepare care plans for older adults with designated long-term care needs from Levels 1 (mild) to 5 (severe). Most older adults certified to need long-term care have a designated care manager.

These two types of institutions are collectively referred as "centers" in this manuscript.

\subsection{Research Instruments}

\subsubsection{Dependent Variable}

Geriatric depression

Depressive state was measured using the Japanese version of the Geriatric Depression Scale-Short Version-Japanese (GDS) [20], which is based on the Short Version [21] of the original Geriatric Depression Scale [22] developed for screening depression in older adults. The Short Version is a selection of 15 of the 30 items found in the original GDS. Subjects answer "yes" or "no" to each item. For the short version, GDS scores can range between 0 and 15 points; a score of $\geq 6$ points is considered indicative of depression [20] [23]. Both instruments have demonstrated good validity and reliability. In this study, the Cronbach's alpha 
was 0.80 , and therefore, internal consistency was confirmed.

\subsubsection{Independent Variables}

1) Aging awareness

Aging awareness was assessed as follows. Present life satisfaction was described using the statement "I feel satisfied with my life now that I have lived for a long time." Aging awareness in the past was described using the statements, "I thought that aging would not be negative when I was young" (positive aging awareness) and "I had a poor image of aging when I was young" (negative aging awareness). Responses involved 6 options ranging from "strongly agree" to "strongly disagree."

2) Health conditions

SF-8 was developed to measure general health status as an indicator of health-related QOL. It consists of the following eight subscales: Physical function (PF), Role physical (RP), Body pain (BP), Social functioning (SF), General health perceptions (GH), Vitality (VT), Role emotional (RE), and Mental health (MH). Each subscale consisted of a total of 100 points, with higher scores indicating better health status. Its reliability and validity have been verified [24].

3) Social networks

The Lubben Social Network Scale is used worldwide as a screening tool for social isolation in elderly individuals. The Lubben Social Network Scale-6 (LSNS-6) is a shortened version of the Social Network Scale developed by Lubben et al. [25] for older adults. Comprising six items, the scores range from 0 to 30 points, with higher scores indicating larger social networks. A score of less than 12 points indicates social isolation. Its reliability and validity have been verified, including that of the Japanese version [26].

4) Supports

Participants were asked if they used any of the following services: home care, home nursing, daycare, or day service centers. In addition, as informal support, participants were asked to respond with "Yes" or "No" to the question, "Do you have a child living in the local area, who can come immediately when needed?"

5) Demographic characteristics

Participants' demographic characteristics included age, gender, duration for which the individual has lived alone, long-term care needs, and economic status.

\subsection{Data Collection}

First, the relevant municipal office responsible for elderly health and welfare in each prefecture was contacted and provided an overview of the study. Collectively, offices reported a total of 1456 community general support centers and 130 in-home long-term care support providers (1586 centers in total). Next, 1140 centers (about 70\%) were extracted using stratified random sampling based on the proportion of single-person households with older adults aged 65 years or older in all neighborhoods within each prefecture. Documentation explaining the research overview and a sample questionnaire form were mailed to each 
center, requesting them to reply by fax with their consent to help with survey distribution and the number of eligible older adults in their care. In total, 265 centers agreed to distribute surveys. Subsequently, questionnaires were sent to all consenting centers, with a request to distribute them to older adults living alone who their care manager deemed capable of filling in. Instructions requested that the older adults themselves fill in the survey, but a family member or designated care support specialist was permitted to do so if this was impractical. Completed questionnaires were sealed in a provided reply envelope, and mailed directly to the researchers by post. Centers distributed 1058 questionnaires to solitary older adults. In total, 738 forms were recovered (response rate: $69.8 \%$ ), of which 3 were excluded for significant omissions. Analysis excluded individuals with missing responses for the GDS items or with dementia, and included only those with long-term care or support needs rated Level 1 or 2 considering that the present study focused only on low-level long-term care. The final analysis population consisted of 457 older adults (effective response rate: 62.2\%). The survey period ran from September to December 2014.

\subsection{Data Analysis}

For the characterization and distribution of the study population, a descriptive analysis was conducted. Correlations between the GDS score and other variables; life satisfaction, aging awareness, health conditions, social networks, and attribution, were calculated using the Spearman's rank correlation. The response of GDS was separated by the cut-off point of a score of 5/6, after which the GDS scores were compared with the chi-squared or Mann-Whitney U tests, to analyze among distribution, life satisfaction, aging awareness, health conditions, and social networks. In examining the predictive factors of depression, the GDS score was entered as the dependent variable in the multiple logistic regression analysis. For all analyses, the significance level was set at 5\% and they were conducted using SPSS ver.22.

\subsection{Ethical Considerations}

A request document different from the survey form was presented to each participant, including a clear and complete explanation of the gist of the study along with the fact that participation in the study is a matter of personal choice and free will. Additionally, participants were informed that refusal to cooperate with the study would entail no disadvantage to any person, in terms of impact or effect on use of services, content of services, etc.; that their personal information would remain confidential; that the possibility of publication of results exists, while maintaining the anonymity of each participant; and that consent to participate in the study would be considered as granted with the return of the completed survey form by the participant. This study was performed after receiving the approval of the nursing study ethical review board of the author's affiliated university at the time of the survey. 


\section{Results}

\subsection{Review of Participants (Table 1)}

In total, 457 participants were recruited. The mean age was $83.9 \pm 6.5$ years, and $53.8 \%$ were aged 85 years or older. Over $60 \%$ of participants used home care and daycare or day service facilities.

\subsection{Distribution of a GDS Score $\geq 6$ among the Participants' Characteristics and Used Services (Table 2)}

Among the participants, $39.8 \%$ had a GDS score of 6 and above. Further, participants aged 65 - 74 years and those requiring economic support tended to exhibit a high tendency for depression.

\subsection{Scores on Various Variables for the Depressed (GDS Score $\geq 6$ ) and Non-Depressed (GDS Score < 6) Groups (Table 3)}

Non-depressed participants had significantly more positive attitudes towards aging in the past and present, higher health-related QOL on all dimensions of the SF-8, and higher social network scores as compared to depressed participants.

\subsection{Characteristics of Geriatric Depression and Related Factors}

Aging life satisfaction at present, negative aging awareness in the past, GH, VT, SF, RE, MH, and social network showed a significant correlation with the GDS score, with a coefficient of 0.3 and above (Table 4).

Regression analysis was conducted for four successive models using sequential variable entry. Model 1 included only one independent variable, aging awareness. Depressive state was significantly associated with current positive attitudes towards aging and past negative attitudes towards aging. Model 2 expanded Model 1 by adding all demographic variables. Depressive state was significantly associated with aging life satisfaction at present $(\mathrm{OR}=0.52)$, negative attitudes towards aging in the past $(\mathrm{OR}=1.35)$, time spent living alone $(\mathrm{OR}=1.02)$, and economic status $(\mathrm{OR}=0.56)$. Model 3 included all variables from Model 2 plus health-related QOL. Depressive state was significantly associated with aging life satisfaction at present $(\mathrm{OR}=0.60)$, negative attitudes towards aging in the past $(\mathrm{OR}=1.387$, and mental health $(\mathrm{OR}=0.93)$. In Model 4 , the GDS score significantly correlated with aging life satisfaction at present $(\mathrm{OR}=0.60)$, negative attitudes towards aging in the past $(\mathrm{OR}=1.38)$, mental health $(\mathrm{OR}=0.93)$, and social networks $(\mathrm{OR}=0.94)$.

Current positive and negative past attitudes towards aging were significantly associated with depressive state in all models (Table 5).

\section{Discussion}

\subsection{Relationship between Elderly Depression and Aging Awareness}

In this study, several related models were constructed by the successive intro- 
duction of independent variables. Model 2 included only aging awareness and participants' characteristics. In this model, depressive state was worse the longer an individual had spent living alone, and better the greater their wealth. However, economic status and solitary living duration's associations disappeared in Model 4, which additionally included various dimensions of health-related QOL and social network richness. Only current positive and past negative attitudes towards aging remained associated with depression. In essence, this demonstrates that depression is influenced by aging awareness in older adults with low-level long-term-care needs, independent of health, social isolation, support from children, time spent living alone, and economic status. In particular, a current, positive attitude towards one's life in old age, along with not regarding aging as negative in one's youth, seem to have a protective effect against depression as people get older. To elaborate, it is difficult to draw the conclusion that depression is influenced by positive perceptions of aging in the past; it seems sufficient to merely avoid embracing such negative views in one's youth.

Table 1. Participants' characteristics.

\begin{tabular}{|c|c|c|c|c|}
\hline & & & \multicolumn{2}{|c|}{$\mathrm{N}=457$} \\
\hline & & & $\mathrm{n}$ & $\%$ \\
\hline \multirow[t]{2}{*}{ Gender } & Male & & 88 & 19.3 \\
\hline & Female & & 369 & 80.7 \\
\hline \multirow[t]{3}{*}{ Prefectures } & A & & 160 & 35.0 \\
\hline & B & & 171 & 37.4 \\
\hline & $\mathrm{C}$ & & 126 & 27.6 \\
\hline \multirow[t]{3}{*}{ Age group (Years) } & $65-74$ & & 45 & 9.8 \\
\hline & $75-84$ & & 166 & 36.3 \\
\hline & $\geq 85$ & & 246 & 53.8 \\
\hline \multirow[t]{4}{*}{ Long-term care needs } & Support needs & Level 1 & 121 & 26.5 \\
\hline & & Level 2 & 127 & 27.8 \\
\hline & Care needs & Level 1 & 134 & 29.3 \\
\hline & & Level 2 & 75 & 16.4 \\
\hline \multirow[t]{4}{*}{ Economic status } & Need full financial support for daily life & & 16 & 3.5 \\
\hline & Need partial financial support & & 51 & 11.2 \\
\hline & Life free of financial worry & & 338 & 74.0 \\
\hline & Has money to spare for children or others & & 44 & 9.6 \\
\hline \multirow[t]{3}{*}{ Used care services $\dagger$} & Visiting service & Home nursing & 43 & 9.4 \\
\hline & & Home care & 278 & 60.8 \\
\hline & Day care center & $\begin{array}{l}\text { Daycare/Day } \\
\text { service }\end{array}$ & 302 & 66.1 \\
\hline \multirow[t]{2}{*}{ Support from a child } & $\begin{array}{l}\text { A child who resides near the person and } \\
\text { can come quickly when needed }\end{array}$ & & 121 & 26.5 \\
\hline & & & \multicolumn{2}{|c|}{ mean \pm SD } \\
\hline Age & & & \multicolumn{2}{|c|}{$83.9 \pm 6.5$} \\
\hline Duration of living alone & & & \multicolumn{2}{|c|}{$14.0 \pm 13.1$} \\
\hline
\end{tabular}

Note $1 . \dagger$ Used services could have multiple responses. Note 2. SD = Standard Deviation. 
Table 2. Distribution of Geriatric Depression Scale scores $\geq 6$ across participant characteristics and used services.

\begin{tabular}{|c|c|c|c|c|c|}
\hline & & & $\mathrm{n}$ & $\%$ & $\mathrm{p}$ value \\
\hline \multirow[t]{3}{*}{ Whole } & Depressive (GDS Score $\geq 6$ ) & & 182 & $39.8 \%$ & \multirow{3}{*}{$<0.001$} \\
\hline & Not depressive (GDS Score $<6$ ) & & 275 & $60.2 \%$ & \\
\hline & & & & GDS Score $\geq 6$ & \\
\hline \multirow[t]{3}{*}{ Age group (Years) } & $65-74$ & & 26 & $57.8 \%$ & \multirow{3}{*}{0.016} \\
\hline & $75-84$ & & 69 & $41.6 \%$ & \\
\hline & $\geq 85$ & & 87 & $35.4 \%$ & \\
\hline \multirow[t]{2}{*}{ Gender } & Male & & 37 & $42.0 \%$ & \multirow{2}{*}{0.636} \\
\hline & Female & & 145 & $39.3 \%$ & \\
\hline \multirow[t]{4}{*}{ Long-term care needs } & Support needs & Level 1 & 41 & $33.9 \%$ & \multirow{4}{*}{0.137} \\
\hline & \multirow{3}{*}{ Care needs } & Level 2 & 51 & $40.2 \%$ & \\
\hline & & Level 1 & 52 & $38.8 \%$ & \\
\hline & & Level 2 & 38 & $50.7 \%$ & \\
\hline \multicolumn{6}{|l|}{ Economic status } \\
\hline & Need full financial support for daily life & & 10 & $62.5 \%$ & \multirow{4}{*}{$<0.001$} \\
\hline & Need partial financial support & & 30 & $58.8 \%$ & \\
\hline & Life free of financial worry & & 129 & $38.2 \%$ & \\
\hline & Having the money to spare for children or others & & 9 & $20.5 \%$ & \\
\hline \multicolumn{6}{|l|}{ Support from a child } \\
\hline & A child lives near the person and can come quickly if needed & Yes & 41 & $33.9 \%$ & \multirow{2}{*}{0.141} \\
\hline & & No & 135 & $40.2 \%$ & \\
\hline \multicolumn{6}{|l|}{ Used care services } \\
\hline & Home Nursing & & 18 & $41.9 \%$ & 0.775 \\
\hline & Home care & & 111 & $39.9 \%$ & 0.955 \\
\hline & Daycare/Day Service & & 121 & $40.1 \%$ & 0.883 \\
\hline
\end{tabular}

Note 1. $\chi^{2}$ test, Note 2. Percentage is ratio of depressive people (GDS Score $\geq 6$ ) in which each variables are $100 \%$, Note 3. GDS = Geriatric Depression Scale, $\mathrm{SD}=$ Standard Deviation.

Table 3. Average scores on each variable between those with (GDS score $\geq 6$ ) and without (GDS score $<6$ ) depression.

\begin{tabular}{|c|c|c|c|c|c|c|c|c|c|}
\hline & & & \multicolumn{3}{|c|}{$\begin{array}{l}\text { Depressive state } \\
\quad(\text { GDS } \geq 6)\end{array}$} & \multicolumn{3}{|c|}{$\begin{array}{l}\text { Non-depressive state } \\
\quad(\text { GDS }<6)\end{array}$} & \multirow[b]{2}{*}{$\mathrm{p}$ value } \\
\hline & & & Mea & $\pm \mathrm{SD}$ & $\mathrm{n}$ & Mea & $\pm \mathrm{SD}$ & $\mathrm{n}$ & \\
\hline Aging awareness at present & & $\begin{array}{l}\text { "I feel satisfied with my life now } \\
\text { that I have lived for a long time" } \dagger\end{array}$ & 3.3 & \pm 1.3 & 178 & 4.3 & \pm 1.1 & 270 & $<0.001$ \\
\hline \multirow[t]{2}{*}{ Aging awareness in the past } & Positively & $\begin{array}{l}\text { "I thought that aging would not be bad when } \\
\text { I was young" } \dagger\end{array}$ & 3.8 & \pm 1.3 & 180 & 4.2 & \pm 1.2 & 271 & $<0.001$ \\
\hline & Negatively & $\begin{array}{c}\text { "I had a poor image of aging when I was } \\
\text { young" } \dagger\end{array}$ & 3.6 & \pm 1.4 & 180 & 3.0 & \pm 1.3 & 271 & $<0.001$ \\
\hline \multirow[t]{2}{*}{ Health-related QOL } & SF-8 & Physical function & 36.9 & \pm 10.8 & 181 & 42.0 & \pm 10.1 & 273 & $<0.001$ \\
\hline & & Role physical & 38.9 & \pm 9.9 & 179 & 43.8 & \pm 9.5 & 274 & $<0.001$ \\
\hline
\end{tabular}




\section{Continued}

\begin{tabular}{|c|c|c|c|c|c|c|c|c|}
\hline & Body pain & 41.6 & \pm 9.0 & 180 & 44.3 & \pm 9.5 & 273 & 0.002 \\
\hline & General health perceptions & 42.4 & \pm 7.4 & 181 & 48.0 & \pm 6.5 & 274 & $<0.001$ \\
\hline & Vitality & 42.9 & \pm 7.0 & 179 & 47.1 & \pm 6.3 & 274 & $<0.001$ \\
\hline & Social functioning & 41.4 & \pm 10.2 & 178 & 47.9 & \pm 9.1 & 274 & $<0.001$ \\
\hline & Role emotional & 42.1 & \pm 9.7 & 177 & 48.6 & \pm 7.2 & 273 & $<0.001$ \\
\hline & Mental health & 43.7 & \pm 7.7 & 177 & 50.5 & \pm 6.9 & 273 & $<0.001$ \\
\hline Social networks & LSNS-6 Score $\$$ & 10.0 & \pm 5.7 & 177 & 13.2 & \pm 5.9 & 269 & $<0.001$ \\
\hline Duration of living alone & (Years) & 15.2 & \pm 13.9 & 176 & 13.3 & \pm 12.5 & 272 & 0.241 \\
\hline
\end{tabular}

Note 1 . Mann-Whitney U test. Note $2 . \dagger$ "strongly disagree" = 1 to "strongly agree" $=6$; $\ddagger$ The maximum score on the SF- 8 is 100 points, with higher scores indicating a better health condition; $\$$ The maximum score on the Lubben Social Network Scale-6 (LSNS-6) is 30 points, with higher scores indicating lower social isolation. Note 3. GDS $=$ Geriatric Depression Scale, SD = Standard Deviation, QOL = Quality of life.

Table 4. Correlations of variables with the GDS score.

\begin{tabular}{|c|c|c|c|c|}
\hline & & & r value & $\mathrm{p}$ value \\
\hline $\begin{array}{c}\text { Aging awareness at } \\
\text { present }\end{array}$ & & $\begin{array}{l}\text { "I feel satisfied with my life now } \\
\text { that I have lived for a long time" } \dagger\end{array}$ & -0.50 & $<0.001$ \\
\hline \multirow[t]{2}{*}{$\begin{array}{l}\text { Aging awareness in the } \\
\text { past }\end{array}$} & Positive & $\begin{array}{l}\text { "I thought that aging would } \\
\text { not be bad when I was young" } \dagger\end{array}$ & -0.18 & $<0.001$ \\
\hline & Negative & "I had a poor image of aging when I was young" $\dagger$ & 0.30 & $<0.001$ \\
\hline \multirow[t]{8}{*}{ Health-related QOL } & $(\mathrm{SF}-8) \ddagger$ & Physical function & -0.28 & $<0.001$ \\
\hline & & Role physical & -0.30 & $<0.001$ \\
\hline & & Body pain & -0.16 & $<0.001$ \\
\hline & & General health perceptions & -0.44 & $<0.001$ \\
\hline & & Vitality & -0.37 & $<0.001$ \\
\hline & & Social functioning & -0.34 & $<0.001$ \\
\hline & & Role emotional & -0.39 & $<0.001$ \\
\hline & & Mental health & -0.45 & $<0.001$ \\
\hline Social networks & & LSNS-6 score $\$$ & -0.32 & $<0.001$ \\
\hline Support from a child & & $\begin{array}{l}\text { A child lives near the individual } \\
\text { and can come quickly if needed }\end{array}$ & -0.04 & 0.412 \\
\hline & & $(\mathrm{Yes}=1, \mathrm{No}=0)$ & & \\
\hline Used care services & & Home nursing & 0.01 & 0.879 \\
\hline \multirow{2}{*}{\multicolumn{2}{|c|}{$($ Use $=1$, Not use $=0)$}} & Home care & 0.03 & 0.560 \\
\hline & & Daycare/Day Service & -0.01 & 0.814 \\
\hline \multirow{4}{*}{ Attributes } & & Gender $($ Male $=1$, Female $=2)$ & -0.02 & 0.723 \\
\hline & & Duration of living alone (Years) & 0.10 & 0.036 \\
\hline & & Long-term care needs level ${ }^{\|}$ & 0.12 & 0.008 \\
\hline & & Economic status & -0.22 & $<0.001$ \\
\hline
\end{tabular}

Note 1. Spearman's rank correlation coefficient. Note 2 . $\uparrow$ Six alternatives from "strongly disagree" = 1 to "strongly agree" $=6$; $\ddagger$ The maximum score on the SF-8 is 100 points, with higher scores indicating a better health condition; $\$$ The maximum score on the Lubben Social Network Scale-6 (LSNS-6) is 30 points, with higher scores indicating lower social isolation; " "support needs level 1" = 1 to "care needs level 2" = 4; "Need of full financial support for daily life" = 0 to "Having the money to spare for children or others". Note 3. GDS = Geriatric Depression Scale, QOL = Quality of life. 
Table 5. Findings of the multiple logistic regression analysis on geriatric depression.

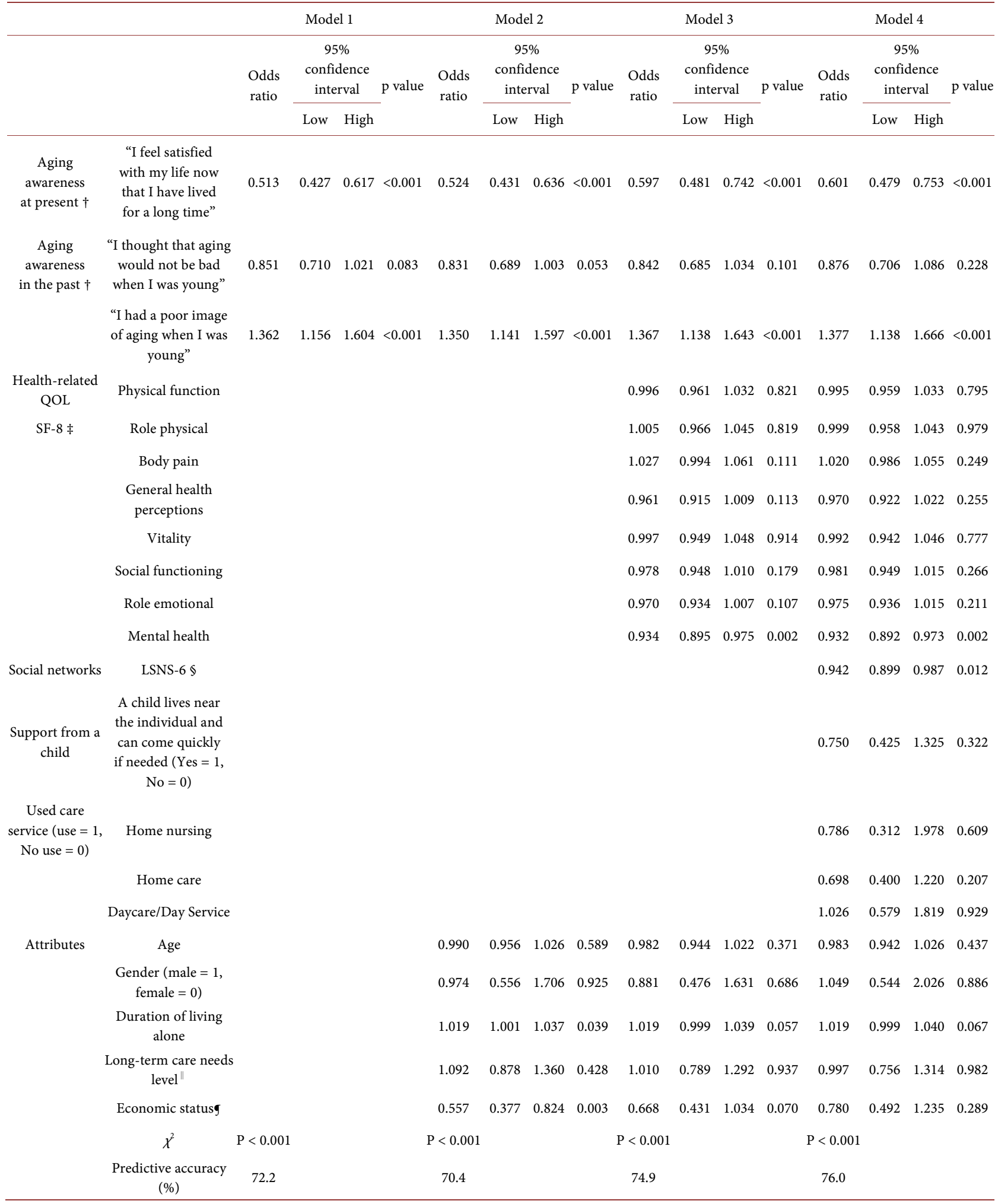

Note 1. Multiple logistic regression analysis. (Geriatric Depression Scale; GDS score $\geq 6$ ) $=1$, (GDS score $<6$ ) $=0$. Note 2 . $†$ Six alternatives from "strongly disagree" $=1$ to "strongly agree" $=6$; $\ddagger$ The maximum score on the SF-8 is 100 points, with higher scores indicating a better health condition; $\S$ The maximum score on the Lubben Social Network Scale-6 (LSNS-6) is 30 points, w ith higher scores ind icating low er social iso lation ; || "support needs level 1" = 1 to "care needs level 2" = 4; "Need full financial support for daily life" = 0 to "Having the money to spare for children or others" = 3. Note 3. QOL $=$ Quality of life. 
Individuals internalize values and beliefs about the aging process through their past encounters with older adults and people with disabilities. Moreover, aging carries a social stigma, as people's health tends to deteriorate as they age [17]. Older adults who held negative attitudes toward aging in the past may transfer those views to themselves once they age and become frail, increasing their risk of depression. Growing up in a society founded on a value system without pessimistic views of old age would likely lead people to attach greater meaning to their own lives in their old age. Accordingly, it is imperative that people learn to regard growing old in a positive light since childhood, that is, early in their life cycle, when they are young and healthy. The society must also strive to promote community activities that allow all generations to view the aging process positively.

\subsection{Effects of Living Alone on Depression in Frail Older Adults}

Social network richness was associated with depressive state in the present study. Frail older adults who live alone encounter many difficult situations in their daily lives; when they arise, they need to be able to handle them by themselves. Moreover, aging-related changes create stressful situations for older adults with long-held negative beliefs about aging. Generally, older adults who live alone have fewer opportunities for regular conversation and interactions with others compared those who cohabit with family members, making them prone to feelings of loneliness, isolation, and poor mental health by extension. Nonetheless, preliminary evidence suggests depression may be improved by individuals' psychological recovery from challenging experiences [27]. Therefore, experiences of overcoming difficulties, and the associated feelings of achievement, are critical to preventing and improving depression in frail older adults who live alone, in addition to providing care support as needed.

\subsection{Suggestions for Improving Elderly Depression and Raising Aging Awareness}

Health care workers need to understand how older adults regard the aging process when determining appropriate care strategies to combat depression in frail older adults living alone. One method to this end is to listen to the individual life stories of older adults-their recollections of older adults they themselves encountered since their childhood years, their interactions with people with disabilities at work, and their thoughts and feelings at those times-and their appraisals of their current selves against this backdrop. Hearing their life stories would allow researchers to confirm their past and present attitudes towards the aging process. Such life story interviews may allow researchers to inquire into the value judgments that frail older adults make about their lives in old age, and identify circumstances that cause them anguish and, in many cases, depression, due to negative self-appraisals guided by their value systems. Making older adults aware of their attitudes towards aging may free them from negative 
thought patterns, which is a major cause of depression.

In addition, since rich social networks reduce depression among the oldest old, it has been proposed that this population be screened for social isolation, and encouraged to participate regularly in their community [28]. Expanding the social networks of solitary-living older adults could alleviate feelings of despondency, thereby improving depression. Support to boost social networks through community activities, such as participation in social activities and interactions with neighbors, are especially important for older adults who live alone; individual connections with their care providers are insufficient. Care providers must provide frail older adults living alone assistance that is customized to their health status and social networks, so that they can better self-manage their health and lives independently. Therefore it will be necessary to discuss continuous about specific supports to improve the quality of life for older adults.

\subsection{Limitations of This Study}

The study participants are limited to only those older adults who have the physical and mental capacities to live alone, and who interact with a care manager. In addition, dementia status was only self-reported, not necessarily officially diagnosed. Hereafter, we will expand our analysis to examine older adults with serious long-term care needs (Levels 3 - 5), as well as to those who do not use care services, in addition to employing a dementia rating scale.

\section{Conclusions}

The present findings suggest that $39.8 \%$ of older adults living along in Japan in need of low-level long-term care suffer from depression. Potential risk factors for depression were analyzed using four models, incorporating the independent variables of past and present attitudes towards aging, personal attributes, health-related QOL, and social network richness. Depressive state was significantly associated with current positive and past negative attitudes towards aging in all models.

Our findings suggest that aging awareness needs to be monitored in frail older adults, and that broad-based community strategies targeting individuals before they grow old themselves are necessary to ensure that people of all generations regard the aging process in positive light. In addition, participation in social activities and engaging with community residents are necessary components of support to expand the social networks of solitary older adults, in order to prevent and improve depression in this population.

\section{Acknowledgements}

The authors would like to thank all older adults who participated in this study and all the provider staff. This study was supported by the Japan Society for the Promotion of Science. 


\section{Conflicts of Interest}

There are no entities or relationships presenting a potential conflict of interest requiring disclosure in relation to this study.

\section{References}

[1] Ministry of Health, Labour and Welfare (2014) Kanjya-chousa. http://www.mhlw.go.jp/toukei/list/10-20.html

[2] Passos, A., do Céu Clara Costa, I., de Andrade, F., do CarmoEulálio, M., Neri, A., de Melo, R. and Lacerda, A. (2015) Prevalence of Frailty Syndrome in the Elderly and Associated Factors in Brazil. Health, 7, 1591-1599.

https://doi.org/10.4236/health.2015.711172

[3] Ahn, S.N., Kim, S. and Zhang, H. (2017) Changes in Depressive Symptoms among Older Adults with Multiple Chronic Conditions: Role of Positive and Negative Social Support. International Journal of Environmental Research and Public Health, 14, 16. https://doi.org/10.3390/ijerph14010016

[4] Chung, S. (2008) Residential Status and Depression among Korean Elderly People: A Comparison between Residents of Nursing Home and Those Based in the Community. Health and Social Care in the Community, 16, 370-377.

https://doi.org/10.1111/j.1365-2524.2007.00747.x

[5] Isaac, V., Stewart, R., Artero, S., Ancelin, M.L. and Ritchie, K. (2009) Social Activity and Improvement in Depressive Symptoms in Older People: A Prospective Community Cohort Study. The American Journal of Geriatric Psychiatry, 17, 688-696. https://doi.org/10.1097/JGP.0b013e3181a88441

[6] Kimura, H. and Kanzaki, N. (2013). A Study on Depression Symptoms Home-Staying Senior Aged 75 and over. Journal of the Japanese Association of Rural Medicine, 61, 915-924. (In Japanese) https://doi.org/10.2185/jjrm.61.915

[7] Enkvist, A., Ekstrom, H. and Elmstahl, S. (2012) Associations between Functional Ability and Life Satisfaction in the Oldest Old: Results from the Longitudinal Population Study Good Aging in Skane. Clinical Interventions in Aging, 7, 313-320. https://doi.org/10.2147/CIA.S33610

[8] Grenade, L. and Boldy, D. (2008) Social Isolation and Loneliness among Older People: Issues and Future Challenges in Community and Residential Settings. Australian Health Review, 32, 468-478. https://doi.org/10.1071/AH080468

[9] Kuzuya, M., Masuda, Y., Hirakawa, Y., Iwata, M., Enoki, H., Hasegawa, J. and Iguchi, A. (2006) High Prevalence Rate of Depression among Community-Dwelling Japanese Frail Elderly. Journal of Japan Academy of Nursing Science, 43, 512-517. https://doi.org/10.3143/geriatrics.43.512

[10] Fukunaga, R., Abe, Y., Nakagawa, Y., Koyama, A., Fujise, N. and Ikeda, M. (2012) Living Alone Is Associated with Depression among the Elderly in a Rural Community in Japan. Psychogeriatrics, 12, 179-185. https://doi.org/10.1111/j.1479-8301.2012.00402.x

[11] Erikson, E.H., Erikson, J.M. and Kivnick, H.Q. (1986) Vital Involvement in Old Age. W.W. Norton \&Company, New York.

[12] Nelson, T.D. (2005) Ageism: Prejudice Against Our Feared Future Self. Journal of Social Issues, 61, 207-221. https://doi.org/10.1111/j.1540-4560.2005.00402.x

[13] Sneed, J.R. and Whitbourne, S.K. (2005) Models of the Aging Self. Journal of Social Issues, 61, 375-388. https://doi.org/10.1111/j.1540-4560.2005.00411.x 
[14] Tanaka, K. and Hasegawa, M. (2012) The Experience of Elderly People Living with Depression. Japan Journal of Nursing Science, 32, 53-62. https://doi.org/10.5630/jans.32.3_53

[15] Tanaka, K. and Hasegawa, M. (2016) Resilience in Patients with Senile Depression from Stories Depicting Their Illness and Recovery. Japan Journal of Nursing Science, 36, 93-102.

[16] Abe, Y., Fujise, N., Fukunaga, R., Nakagawa, Y. and Ikeda, M. (2012) Comparisons of the Prevalence of and Risk Factors for Elderly Depression between Urban and Rural Populations in Japan. International Psychogeriatrics, 24, 1235-1241. https://doi.org/10.1017/S1041610212000099

[17] Jee, Y.J. and Lee, Y.B. (2013) Factors Influencing Depression among Elderly Patients in Geriatric Hospitals. Journal of Physical Therapy Science, 25, 1445-1449. https://doi.org/10.1589/jpts.25.1445

[18] Atchley, R.C. and Barusch, A.S. (2004) Social Forces and Aging: An Introduction to Social Gerontology. 10th Edition, Wadsworth Publishing, Belmont.

[19] Cabinet Office, Government of Japan (2014) Kourei-syakai-hakusyo. http://www8.cao.go.jp/kourei/whitepaper/w-2013/zenbun/s1_1_2.html

[20] Sugisita, M. and Asada, T. (2009) Koureisya you utusyakudo tansyukuban nihonban (Geriatric Depression Scale Short Version-Japanese, GDS-S-J) no sakusei nituite. Japanese Journal of Cognitive Neuroscience, 11, 87-90. (In Japanese)

[21] Sheikh, J. and Yesavage, J.A. (1986) Geriatric Depression Scale (GDS): Recent Evidence and Development of a Shorter Version. Clinical Gerontologist, 5, 165-173. https://doi.org/10.1300/J018v05n01_09

[22] Yesavage, J.A., Brink, T.L., Rose, T.L., Lum, O., Huang, V., Adey, M., et al. (1982) Development and Validation of a Geriatric Depression Screening Scale: A Preliminary Report. Journal of Psychiatric Research, 17, 37-49. https://doi.org/10.1016/0022-3956(82)90033-4

[23] Watanabe, M. and Imagawa, T. (2013) Factor Structure of the Short Form of the Geriatric Depression Scale (GDS): Reliability, Validity and Cutoff Points. The Japanese Journal of Personality, 22, 193-197. https://doi.org/10.2132/personality.22.193

[24] Fukuhara, S. and Suzukamo, Y. (2004) Manual of the SF-8 Japanese Version: Institute for Health Outcome \& Process Evaluation Research. Public Health Research Foundation, Kyoto.

[25] Lubben, J.E. and Gironda, M.E. (2003) Centrality of Social Ties to the Health and Well-Being of Older Adults. In: Berkman, L. and Harooytan, L., Eds., Social Work and Health Care in an Aging World, Springer Press, New York, 319-350.

[26] Kurimoto, A., Awata, S., Ohkubo, T., Tsubota-Utsugi, M., Asayama, K., Takahashi, K., Suenaga, K., Satoh, H. and Imai, Y. (2011) Reliability and Validity of the Japanese Version of the Abbreviated Lubben Social Network Scale. Japanese Journal of Geriatrics, 48, 149-157. https://doi.org/10.3143/geriatrics.48.149

[27] Fontes, A.P. and Neri, A.L. (2015) Resilience in Aging: Literature Review. Cien Saude Colet, 20, 1475-1495. https://doi.org/10.1590/1413-81232015205.00502014

[28] Aung, M.N., Moolphate, S., Aung, T.N., Katonyoo, C., Khamchai, S. and Wannakrairot, P. (2016) The Social Network Index and Its Relation to Later-Life Depression among the Elderly Aged $\geq 80$ Years in Northern Thailand. Clinical Interventions in Aging, 8, 1067-1074. https://doi.org/10.2147/CIA.S108974 